\title{
DESORDENANDO O MONOPÓLIO TERRITORIAL ESTATAL: APORTES TEÓRICOS DA GEOGRAFIA CRÍTICA À RECONFIGURAÇÃO PLURINACIONAL DO ESTADO EQUATORIANO ${ }^{1}$
}

\section{Desordenando el monopolio territorial estatal: aportes teóricos de la geografía crítica a la reconfiguración plurinacional del Estado}

\author{
Manuela Monarcha Murad da Silveira \\ Mestre em Geografia pela UFF \\ manuelamms@hotmail.com
}

Artigo recebido em 05/04/2021 e aceito em 04/05/2021

DOI: $10.12957 /$ tamoios.2021.58368

A finais de 2012, quando as contradições dos primeiros quatro anos da Revolución Ciudadana se intensificavam, foi formado o Colectivo de Geografía Crítica del Ecuador, reunindo pesquisadores(as) e ativistas interessados(as) na construção de uma análise espacial multiescalar, que possibilitasse entender as tensões territoriais latentes em um Equador recém reconhecido como Estado plurinacional. Em uma conjuntura geopolítica em que a exploração da natureza-recurso alcançava seu ponto culminante, os inovadores direitos territoriais constitucionalmente reconhecidos em 2008 - a plurinacionalidade e interculturalidade do Estado, a autonomia territorial, o direito à consulta prévia, livre e informada e o pluralismo jurídico, para citar alguns - não eram suficientes para frear os atropelos às territorialidades dos povos e comunidades tradicionais ${ }^{2}$. De fato, a ambiguidade da Constituição Equatoriana, com seu apelo concomitante à plurinacionalidade e ao sujeito abstrato da cidadania moderna, abria espaço para um projeto de governo neo-desenvolvimentista que sobrepunha explicitamente o interesse nacional - supostamente universal - aos interesses/direitos comunitários, enfraquecendo e deslegitimando a estes últimos.

Neste contexto, salvo raras exceções, a Geografia equatoriana se limitava a uma ferramenta técnica e supostamente neutra para o ordenamento territorial estatal ${ }^{3}$. Frente a isso, nos pareceu fundamental construir uma reflexão crítica sobre as dinâmicas territoriais do Estado e as sutis - porém eficientes - estratégias discursivas que legitimam o monopólio territorial do Estado por sobre os direitos territoriais dos povos e comunidades tradicionais. Tendo como base principalmente os conceitos de território/territorialidade, (des)ordenamento territorial e des-re-territorialização, construímos uma leitura sobre as dinâmicas, mudanças e limites relativos à reconfiguração do Estado equatoriano em base plurinacional, o que nos permitiu refutar as tradicionais representações e imaginários espaciais que povoam o sentido comum e a política institucional no Equador.

Como parte deste esforço coletivo por construir uma nova geografia no Equador - e desejando que novas e plurais geo-grafias sejam possíveis -, sistematizamos neste artigo algumas reflexões que tiveram um papel central na nossa práxis. Em primeiro lugar, apresentamos uma leitura descolonial sobre o processo histórico de legitimação do monopólio territorial estatal, ressaltando o papel da associação naturalizada entre Estado, nação e território. Em seguida, fazemos uma revisão teórica sobre o conceito de território e de (des)ordenamento territorial, em sua relação com o processo de reconfiguração crítica da Geografia. Por fim, tecemos breves comentários sobre o que denominamos "nódulos territoriais críticos" no Equador, definidos como aqueles "temas não resolvidos 
e geralmente conflitivos da formação territorial, em que se chocam interesses do Estado (geralmente associado ao capital) e das populações locais" (BONILLA et al., 2016: 68).

\section{Estado-nação-território: o longo processo de legitimação do totalitarismo territorial}

A ideia que serve de fio condutor para nossa análise sobre o processo de legitimação do monopólio territorial do Estado é a compreensão da Modernidade (ou Moderno-colonialidade) como processo gradual de conformação de um novo padrão de poder - mundial, capitalista, estatal, patriarcal e eurocêntrico - que passa a reger de forma hegemônica as relações socioespaciais a partir da conquista da América (LANDER, 2005). Esse padrão de poder não se restringe a aspectos econômicos, relativos à difusão do capitalismo, mas também se expressa em múltiplas e hierarquizadas relações políticas, culturais e espaciais. Por meio da fundação de uma nova epistemologia com pretensões universais, a diversidade de saberes (e de territórios) foi progressivamente anulada e os diferentes sistemas de vida marginalizados e oprimidos em nome da civilização e, posteriormente, do progresso e do desenvolvimento.

Com base nessa perspectiva teórico-metodológica adotada - os estudos descoloniais -, entendemos o Estado moderno como "uma forma específica [geográfica] e historicamente localizada" (MORAES, 2005: 51) que conseguiu se afirmar material e subjetivamente como modelo superior e universal de relação entre sociedade e política. A Moderno-colonialidade inaugura a primazia do Estado através de um processo complexo e de longa duração, no qual a centralização dos poderes em uma estrutura administrativa burocratizada e espacialmente delimitada foi sendo imposta a outras formas de organização societal. Para isso, foram mobilizadas tanto estratégias simbólicas como materiais de dominação, variáveis ao longo do tempo e do espaço.

A sociedade política medieval, estruturada com base no regime feudal, estava marcada pela fragmentação da soberania e pela descentralização de poderes, o que se refletia na existência não concorrente de uma multiplicidade de jurisdições e/ou territorialidades sobrepostas entre si (HAESBAERT, 2007b). No século XV, com o renascimento do comércio no mar Mediterrâneo e a progressiva substituição da antiga economia natural - baseada no intercâmbio e na subsistência - por uma economia de mercado, as atribuições do rei começaram a se expandir, levando a uma progressiva centralização do poder, que deu origem a uma monarquia de direito divino marcada pelo caráter absoluto do poder real.

A concretização desse poder ocorreu através da imposição de inúmeras medidas, cujo objetivo principal era unificar e ordenar o nascente Estado Absolutista: formação de um exército próprio; unificação de pesos e medidas; cobrança de impostos em dinheiro; criação de leis; e estabelecimento de uma jurisdição sobre a qual o poder soberano tinha validade inquestionável - o território estatal. O território funcionava, assim, como uma referência espacial para o exercício do poder estatal; mais do que um simples espaço de controle ou escala de mando, o território era "indispensável à existência do Estado" (SOUZA, 1998: 204). Ao contrário do "espaço-tempo do vivido" - sempre múltiplo, diverso e complexo - o território estatal nascia como uma área delimitada sobre a qual o Estado, absolutizado pela figura do rei, exercia sua soberania, não admitindo a multiplicidade/sobreposição de jurisdições e/ou territorialidades (HAESBAERT, 2007b).

O entendimento do território como "uma prerrogativa natural do Estado, atributo do Estado" (PORTO-GONÇALVES, 2003: 259) levou à consolidação de uma leitura do território como espaço exclusivamente vinculado ao Estado, processo para o qual a Geografia exerceu um papel fundamental. De fato, a palavra geógrafo surge no século XVI para denominar os funcionários do rei responsáveis pela elaboração de mapas, 
especialistas inseridos em um segmento burocrático racionalizante que surgia com o objetivo de organizar e controlar o espaço (PORTO-GONÇALVES, 2003). Nesse contexto, a Geografia, longe de constituir um conhecimento científico, consistia em um saber prático, relacionado a estratégias de controle que tinham como base a representação do espaço e a delimitação das fronteiras.

Empreendidas por uma classe emergente de comerciantes apoiada pelo rei, as mudanças ocorridas durante o longo processo que se estende do século $\mathrm{X}$ ao $\mathrm{XV}$ fundam as bases do sistema capitalista e da propriedade privada dos meios de produção, criando as condições estruturais para o surgimento de uma nova institucionalidade política: o Estado. Existe, portanto, uma relação direta entre o aumento do poder real e a expansão do comércio e da indústria: a ação unificadora empreendida pelo Estado era essencial para a expansão mercantilista (PORTO-GONÇALVES, 2001a) e tem como prerrequisito a desarticulação de formas de vida e de organização comunitárias. A forma Estado, assim como a Geografia e o ordenamento territorial, nascem, portanto, aliadas ao capital, representando e atendendo aos interesses da burguesia em ascensão.

Mas foi a partir da Revolução Francesa, com "a ascensão triunfal do liberalismo como embasamento filosófico e ideológico do capitalismo mundial" (DÍAZ-POLANCO, 2004: 26), que o Estado adquiriu os contornos e a base político-ideológica que conhecemos hoje. A ruptura da burguesia com o absolutismo monárquico de direito divino inaugura um Estado ainda mais centralizado, estruturado com base na igualdade individual, na cidadania, na soberania popular e em um território, agora nacional. Antes fundado na vontade do monarca, este novo Estado passa a ter como base o princípio da vontade geral, entendida como a vontade do povo, o que engloba, em teoria, os membros de uma sociedade nacional que aceitam se submeter a certas regras para o alcance do bem comum, ou seja, os cidadãos. Entretanto, o conceito de cidadania universal estabelecia limites à participação popular: nem todos podiam participar igualmente do Estado; mulheres, não-proprietários e analfabetos não eram considerados cidadãos. Ou seja, a universalidade e a igualdade abstrata da cidadania moderna, ainda que tenham ampliado os direitos individuais - antes restritos a uma elite -, ocultam o caráter patriarcal, classista e racista do Estado e se contradizem com a crescente desigualdade e inequidade econômica das sociedades industriais.

O processo de formação deste Estado se amparou fortemente no nacionalismo, princípio segundo o qual "deve haver congruência entre a unidade nacional e política" (GELLNER, 1988: 13). Essa congruência foi buscada nos dois principais modelos de Estado-nação - o modelo universalista e o modelo jus sanguinis ${ }^{4}$-, ainda que cada um tenha como base concepções distintas para justificar a conformação de uma sociedade nacional de destino, territorializada e soberana. Para isso, foram criados e estrategicamente difundidos elementos identitários pretensamente nacionais (materiais, sentimentais e/ou simbólicos) - principalmente o idioma, o território e a história nacional -, o que permitiu construir e legitimar uma imagem de comunidade, contribuindo assim para a criação de uma unidade cultural, política e jurídica para cada território estatal.

Nesse contexto, "a nação passa a existir através dos discursos dos indivíduos que estão interessados na criação dessa realidade particular" (GONZÁLEZ, 2007: 11), tratando-se, portanto, mais de um mito (GELLNER, 1988) do que de uma realidade, uma invenção que buscou forjar uma identidade nacional única a partir dos interesses de um grupo específico que visava assegurar politicamente seus privilégios ${ }^{5}$. A unificação entre projeto político e projeto cultural garantia a coesão nacional e, apoiada nesta, a moderação dos conflitos internos latentes, homogeneizando (sutil ou explicitamente) as diferentes formações culturais internas por meio da ideia de nação e de indivíduo abstrato da cidadania. 
O domínio territorial, antes legitimado pelo poder soberano do rei, passa a se legitimar com base no interesse nacional e na soberania popular. Desde então, o Estadonação monopoliza os procedimentos de organização do espaço, através de imposições totalitárias que definem e delimitam seu(s) uso(s) (POULANTZAS, 1981). O ordenamento territorial é um dos meios através do qual se impõe tradicional e legitimamente a soberania estatal, por meio principalmente da densificação da malha territorial do Estado, com o que se fortalece também seu poder infraestrutural, definido por Mann como "a capacidade do Estado de realmente penetrar a sociedade civil e de implementar logisticamente as decisões por todo o seu domínio" (1992: 169). O processo de fortalecimento desse poder tem início com a formação dos Estados nacionais (na América Latina, no século XIX) e se intensifica radicalmente ao longo do século XX, até adquirir sua face mais brutal, na primeira década do século $\mathrm{XXI}^{6}$.

Fundadas no conceito legal de soberania, que postula a exclusividade do controle de seu território nas mãos do Estado, tanto a "nação-contrato" quanto a "nação-espírito" (SCHNAPPER, 1994) aglutinam a diversidade em torno a um padrão monocultural totalitário e marginalizam as outras formas de organização política, cultural e territorial através de uma identidade nacional forjada de cima para baixo, longe da experiência do vivido. Ainda que se reconhecesse a plurinacionalidade do Estado (inclusive de forma explícita, no caso do modelo universalista), a ela não correspondia uma pluriterritorialidade, já que, nesse contexto, o território era entendido como exclusividade do Estado e da comunidade nacional. Dessa forma, o debate plurinacional foi esvaziado e as culturas não-hegemônicas (ditas "menores") ficaram fadadas à assimilação pela nação dominante ${ }^{7}$. Assim, o Estado-nação, "entidade com a qual o racionalismo liberal celebra seu êxito, traz em seu bojo o gérmen do conflito em sua própria pluralidade, já que no Estado-nação permanece latente o conflito da diversidade" (DÍAZ-POLANCO, 2004: 35).

Aqui é importante ressaltar uma característica marcante das sociedades fundadas a partir das revoluções burguesas: a ideia de que, com base na força coercitiva, o Estado, além de centralizar a função de manutenção da ordem, pode para isso fazer uso, dentre outras estratégias, da violência autorizada e legitimada (GELLNER, 1988). Nas sociedades moderno-coloniais, o Estado é, portanto, um agente (ou conjunto de agentes) fortemente centralizado e disciplinado que detém o monopólio da violência supostamente legítima (GELLNER, 1988). Foi, portanto, com base no ordenamento territorial totalitário (muitas vezes confundido com meras ações técnicas e administrativas) e na violência auto autorizada, tanto concreta quanto simbólica, que se deu a imposição da malha territorial estatal-nacional. Este processo ocorreu por meio da desqualificação e da desarticulação das práticas e costumes dos diferentes povos, marcados por formas distintas de organização política, econômica e territorial, que buscou-se unificar sob um mesmo padrão ${ }^{8}$.

Essa concepção, segundo a qual o Estado detém o monopólio territorial, marcou a origem da Geografia Política, servindo de base até recentemente ao conceito de território; a partir de então, o político e o território passaram a se confundir com o Estado, que se tornou o agente superior e exclusivo de (des)ordenamento territorial da sociedade.

\section{Por uma leitura crítica e politizada do (des)ordenamento territorial}

A Geografia - isso serve, em primeiro lugar, para fazer a guerra (LACOSTE, 1990 [1976]), assim se chamou o livro que revolucionou a maneira tradicional de entender e fazer Geografia, tanto como disciplina acadêmica como escolar. Com seu polêmico título, o geógrafo francês pretendia explicitar os vínculos ocultos entre a Geografia, os 
Estados e os grandes aparatos capitalistas. Até então, a imagem consagrada da Geografia no senso comum era de uma disciplina "inofensiva", associada à memorização de acidentes geográficos e à confecção de mapas, entendidos de forma geral como um retrato fiel da realidade. Enquanto isso, para os Estado e as empresas, a Geografia sempre havia sido considerada um saber estratégico para "fazer a guerra": o conhecimento sobre o espaço se associava à política num sentido mais amplo, sendo essencial para conhecer, organizar e controlar o espaço e a população sobre os quais o aparato do Estado exerce sua autoridade.

A análise de Lacoste nos mostra que o papel da Geografia para o fortalecimento dos Estados e das empresas foi além de sua importância como conhecimento estratégico: a partir de sua institucionalização como disciplina acadêmica e escolar no século XIX, a Geografia passou a exercer um papel fundamental no processo de legitimar nos imaginários coletivos o monopólio do Estado como ordenador do território. A construção de um discurso que associava de forma natural o Estado a uma identidade (nacional) e a um território compartilhados foi amplamente apoiada pela difusão do conhecimento geográfico nas escolas e universidades, o que terminou por naturalizar a associação Estado-nação-território de maneira acrítica. Através desse processo, conseguiu-se legitimar a imposição arbitrária da malha territorial estatal através de um (des)ordenamento territorial que se apresentava como neutro, ocultando sua articulação com interesses específicos impostos sobre a diversidade cultural e territorial existente no interior no Estado-nação.

Esse poderoso imaginário coletivo começa a ser questionado a partir dos anos 1970, tanto no âmbito acadêmico quanto no interior dos movimentos sociais, que passaram a se organizar com base em novas estratégias discursivas, dando uma centralidade cada vez maior ao território. Os movimentos territoriais/identitários (indígenas, afrodescendentes, de periferias urbanas, etc.) se mobilizaram a partir de então pelo reconhecimento da diversidade cultural, o que trouxe à tona o fato de que os Estados nacionais, longe de estarem constituídos por uma unidade cultural e territorial homogênea, se constituem por uma enormidade de particularidades culturais que são sistematicamente atropeladas pelo ordenamento territorial estatal. Articulados em torno a demandas por território e autonomia, esses movimentos explicitaram a existência de formas diversas de apropriação e uso do território, assim como de maneiras distintas de se relacionar com a natureza e de se organizar jurídica, política e economicamente.

Em diálogo com estes movimentos e, sobretudo, com as ciências políticas, a Geografia também passou por um período de reformulação crítica a partir do qual a suposta neutralidade da produção acadêmica e escolar começou a ser questionada. A "nova geografia" ampliou sua compreensão do político e do território, cujo entendimento deixou de estar vinculado exclusivamente ao Estado. O território e as relações de poder passaram a ser entendidos a partir de uma perspectiva mais ampla, que lhes dá um sentido multidimensional e multiescalar, jamais restritos ao espaço e ao poder exclusivistas do Estado-nação (HAESBAERT, 2007a). A partir dessa ampliação, o território pode ser entendido como "uma das formas de marcar, de demarcar a terra, de grafá-la", dizendo respeito "àquela dimensão de espaço que é tornado próprio" (PORTO-GONÇALVES, 2003: 258).

Este processo de demarcar a terra, que se traduz em apropriação e/ou dominação de um espaço, é realizado pela ação de diferentes sujeitos ou grupos sociais, sendo pautado tanto por relações simbólico-culturais quanto por relações materiais/funcionais estabelecidas com o espaço, quer dizer, se refere tanto a apropriações no sentido de dominação material quanto simbólica (HAESBAERT, 2008). Território funcional e território simbólico seriam dois tipos ideais, nunca se manifestando em estado puro: "todo 
território 'funcional' tem sempre alguma carga simbólica, por menos expressiva que ela seja, e todo território 'simbólico' tem sempre algum caráter funcional, por mais reduzido que ele seja" (HAESBAERT, 2008: 22). O território é, portanto, ao mesmo tempo e obrigatoriamente, em diferentes intensidades, funcional e simbólico: "não há apropriação material, incluindo a apropriação da natureza (...), que não seja, ao mesmo tempo, uma apropriação simbólica. Afinal, só se apropria daquilo que tem/faz sentido, que tem um significado. (PORTO-GONÇALVES, 2003: 33).

Haesbaert (2008), no entanto, faz distinção entre a produção de territórios por parte dos dominantes e dos dominados. Os primeiros privilegiam o caráter funcional e mercantil do território, enquanto para os segundos, por ser garantia de sua sobrevivência cotidiana, o território apresenta um caráter tanto funcional quanto simbólico: "para os 'hegemonizados' o território adquire muitas vezes tamanha força, que combina com intensidades iguais funcionalidade ('recurso') e identidade ('símbolo'). Assim, para eles, literalmente, (...) perder seu território é desaparecer" (HAESBAERT, 2008: 22). Em geral, entretanto, a dominação político-econômica se impõe sobre a apropriação culturalsimbólica: como "legítimo" ordenador do território e tendo como base o conceito de propriedade privada, o Estado - em associação com o capital - expande sua malha territorial de maneira arbitrária, impondo sua lógica e interesses sobre as demais territorialidades existentes no espaço nacional.

O conceito de (des)ordenamento territorial (GUERRA, 2012) é fundamental para explicitar este processo. Trata-se de uma releitura crítica do conceito de ordenamento territorial a partir do ponto de vista daqueles que sofrem as ações do Estado. $\mathrm{O}$ termo busca explicitar que o ordenamento está necessariamente vinculado a seu oposto - $\mathrm{o}$ desordenamento -, já que significa sempre a ruptura de outras ordens preexistentes no espaço sobre o qual a malha territorial estatal arbitrariamente se impõe. É fundamental ressaltar que o (des)ordenamento traz como consequência a des-re-territorialização ${ }^{9}$ precária de populações empobrecidas e racializadas, na medida em que as diferentes classes e etnias possuem diferentes e desiguais possibilidades de impor sua territorialidade em momentos de disputa pelo uso e apropriação do espaço.

As classes empobrecidas são precariamente des-re-territorializadas, em geral, através de desapropriação e deslocamentos compulsórios que geram "efetiva instabilidade ou fragilização territorial" e impossibilidade "de construir e exercer efetivo controle sobre seus territórios, seja no sentido de dominação político-econômica, seja no sentido de apropriação simbólico-cultural" (HAESBAERT, 2007a: 312), comprometendo assim sua capacidade de sobrevivência mais básica. Os grupos hegemônicos, pelo contrário, têm enorme facilidade para locomover-se e conectar-se em/com diferentes lugares do mundo, assim como para impor seus investimentos, apropriando-se de espaços já ocupados e criando verdadeiros enclaves no território. No contexto capitalista de acumulação flexível, em que as relações sociais são "construídas através de territóriosrede, sobrepostos e descontínuos" (HAESBAERT, 2007a: 338), os conflitos territoriais e os processos de des-re-territorialização precária e segregada se acentuam.

\section{Formação territorial e "nódulos territoriais críticos" do Equador plurinacional ${ }^{10}$}

A ampliação dos conceitos e a perspectiva histórica sobre o processo de legitimação do monopólio territorial do Estado nos permite realizar uma leitura politizada sobre as marcas do processo de formação territorial do país e os principais "nódulos territoriais críticos" no Equador plurinacional. O longo processo de conformação do que hoje constitui o território nacional equatoriano ocorreu com base em quatro características estruturais básicas: 1) a expropriação e a concentração de terras; 2) a exploração da 
natureza; 3) o racismo e a consequente exploração da força de trabalho indígena e negra; e 4) a produção primário-exportadora (AYALA MORA, 1999). A dinâmica de (des)ordenamento das territorialidades preexistentes não ocorreu de maneira uniforme no território nacional, mas sim de acordo com as diferentes frentes de invasão ${ }^{11}$ acionadas em função das possibilidades de investimento econômico que as diferentes regiões representavam em cada etapa do desenvolvimento capitalista do país. Nesse sentido, tiveram um papel importante não somente o que em cada momento histórico era valorizado como recurso natural, mas também a localização estratégica de cada sitio e a existência de força apropriável para o trabalho.

As dinâmicas de ocupação e exploração do território tiveram como protagonistas dois grupos hegemônicos históricos: a burguesia mercantil do litoral do Pacífico (Costa), sediada em Guayaquil, e os grandes proprietários rurais da Cordilheira Andina (Sierra), que tiveram um papel fundamental no processo de conformação da sociedade política nacional. $\mathrm{O}$ Estado equatoriano não se fundou, portanto, sobre uma identidade nacional prévia, que articulasse diferentes setores da sociedade, mas sim sobre um pacto entre as elites criollas $^{12}$ que criaram fórmulas constitucionais e jurídicas com base em uma cidadania restrita - fortemente assentada sobre a distinção e a desigualdade étnica/racial - que em nada correspondiam à complexa e heterogênea realidade social equatoriana (AYALA MORA, 1992). Os valores universais sobre os quais se funda o constitucionalismo moderno conviviam com a existência de escravos e servos tratados como coisas, vendidos como parte das haciendas ${ }^{13}$ andinas e dos latifúndios litorâneos (AYALA MORA, 1992).

A República equatoriana nasce, portanto, assentada sobre a exclusão legal e social da grande maioria da população, cujos interesses e demandas não foram incluídos no projeto "nacional". Face à impossibilidade de se remeter a uma herança nacional histórica para a criação de uma justificativa nacional que legitimasse a formação do novo Estado independente, o território foi tomado como base de referência principal da unidade nacional. Assim, a centralidade da dimensão territorial ganhou um novo sentido: se durante a colônia sua importância se devia aos imperativos de conquista e controle do espaço invadido, com a independência o território passa a ser o fundamento principal do imaginário político que legitima interna e externamente a soberania do novo Estado (MORAES, 1994). Além disso, a conquista e a ocupação de novos espaços eram fundamentais para a afirmação e proteção das fronteiras do Estado nascente, considerando que grande parte do território reivindicado como nacional era pouco ou nada integrado ao núcleo histórico colonial.

Ao constitucionalismo excludente e à manutenção de uma hegemonia criolla a partir da independência, se somou a inserção cada vez mais dependente da economia equatoriana no sistema-mundo capitalista, através da subordinação de suas atividades produtivas a poderes externos e da consolidação de uma economia primário-exportadora, causa de seguidas crises econômicas durante o período republicano. A exploração voraz e destruidora da natureza e das populações locais continuou sendo a base do sistema produtivo, cuja expansão se dava com base na incorporação de novas áreas, através do (des)ordenamento territorial.

Atualmente, as tendências históricas de uso e ocupação dos espaços se alteraram em diferentes intensidades de acordo com a região, mantendo, no entanto, suas características estruturais básicas e acentuando os conflitos de interesses entre Estado e capital, por um lado, e povos e comunidades por outro. De fato, o novo ordenamento do território nacional se insere em uma nova geopolítica levada a cabo globalmente na qual a exploração da "natureza-recurso" ocupa o papel principal. As áreas do planeta ricas em potencial energético, biodiversidade e recursos minerais - em geral localizadas nos 
chamados países "em desenvolvimento", mais especificamente nos territórios de populações tradicionais (camponeses, indígenas, afro-descendentes), tornaram a ganhar importância estratégica ${ }^{14}$ (PORTO- GONÇALVES, 2001b).

Em explícita alusão ao Consenso de Washington, Svampa denomina a esta nova etapa de acumulação de "Consenso dos Commodities", explicitando a passagem de um projeto neoliberal a um projeto "baseado na extração e exportação de bens primários a grande escala, sem maior valor agregado, aos países mais poderosos" (SVAMPA, 2012: 5). A implantação deste novo consenso na América Latina nos últimos vinte anos reforçou a importância das chamadas "economias de enclave", escassamente encadeadas aos processos produtivos nacionais, "configurando espaços socioprodutivos dependentes do mercado internacional e da volatilidade de seus preços" (SVAMPA, 2012: 5). Além de significar a manutenção de uma dependência externa que se arrasta desde o tempo colonial, tal processo gera riscos e impactos ambientais, assim como uma forte fragmentação social e regional.

Porto-Gonçalves denomina "geopolítica da biodiversidade" (2006: 279) a esta "máxima expressão da despossessão econômica e destruição ambiental" (SVAMPA, 2012: 6), em que se acentuam as relações espaciais desiguais através da imposição das malhas territoriais programadas (tecnopolíticas) às malhas territoriais do espaço vivido (sociopolíticas) (BECKER, 1990). Caracterizada pelo desencaixe "entre os lugares que detêm a tecnologia e os lugares que detêm a diversidade biológica e cultural", esta geopolítica atualiza e acentua "o histórico e desigual padrão de poder moderno-colonial" (PORTO-GONÇALVES, 2006: 279) tanto a nível interestatal - reforçando o papel dos países latino-americanos como "sociedades exportadoras de Natureza" (SVAMPA, 2012: 5) - como intraestatal - incrementando o atropelo aos direitos territoriais dos povos e comunidades.

De fato, os novos investimentos do capital (nacional e estrangeiro) no Equador ocorrem através da densificação da malha territorial do Estado sobre os chamados espaços intersticiais (LITTLE, 2004), ou seja, aqueles que até então haviam sido ignorados pelas diferentes ondas de ocupação e apropriação do território nacional, seja pela inexistência de condições técnicas para extrair lucro de determinadas áreas, seja por não se caracterizarem como áreas de interesse econômico segundo os modelos prévios de acumulação de capital. São esses espaços, no entanto, os que restaram para as populações racializadas após os seguidos processos de des-re-territorialização; o paradoxo é que foi justamente a marginalização econômica e a invisibilização social de seus territórios - que os excluía da área de alcance das políticas públicas - o que historicamente lhes proporcionou uma maior autonomia na tomada de decisões vinculadas a seus espaços de vida e (re)produção. Com a expansão da malha territorial do Estado a essas margens majoritariamente em associação com a iniciativa privada - a arena para a eclosão das tensões territoriais está montada.

\section{Considerações finais}

Neste artigo, tratamos de tecer brevemente as bases teórico-metodológicas que guiaram nossa leitura crítica sobre os sucessivos processos de (des)ordenamento territorial estatal no Equador. Reconhecemos, além disso, o papel da Geografia na legitimação do território e do (des)ordenamento territorial como dimensões exclusivamente vinculadas ao Estado e oferecemos algumas chaves para a leitura crítica dos conflitos territoriais da atualidade no país. A revisão teórica permite entender que o Estado-nação comporta distintas territorialidades sobrepostas no interior do território nacional, as quais sempre foram oprimidas e/ou marginalizadas com base no princípio da 
soberania, segundo o qual o território estatal não admite a pluralidade de poderes e, portanto, de territórios. Além disso, abre a possibilidade de reconhecer os diferentes grupos socioculturais como agentes legítimos de ordenamento de seus espaços de vida e (re)produção, em contraposição ao monopólio territorial do Estado e ao (des)ordenamento territorial estatal.

Entendemos que, apesar da importância de desconstruir discursos e imaginários geográficos, a ruptura com a legitimidade de que tratamos se choca com fortes poderes estatais e corporativos, que inclusive trataram nas duas últimas décadas de vincular uma vez mais o conceito de território ao de Estado, através de sua associação à ideia de governo/poder local, inserido na divisão político-administrativa estatal preexistente. Nesse contexto, parece-nos fundamental recuperar a importância da reapropriação crítica do conceito de território por parte dos movimentos sociais e da própria Geografia no país. Se entendemos que as mudanças políticas e ideológicas são a base fundamental para a construção de uma sociedade etnicamente mais justa, devemos assumir que essas mudanças requerem transformações territoriais na distribuição do poder que vá além da inclusão/enquadramento nas estruturas preexistentes do Estado-nação. Isso porque as formas de organização e gestão do território possíveis neste âmbito continuam sendo coloniais.

A garantia de condições dignas e plurais de vida e (re)produção, ancoradas num verdadeiro respeito pela diversidade de culturas e pela natureza - como reconhece a Constituição -, só é possível se a cada um dos grupos identitários for garantida a sua realização autônoma. Longe de significar a independência total, isolamento ou essencialização, significa reconhecer que as culturas são fruto de um jogo constante entre essencialização e mistura, entre momentos alternados de troca cultural - que originam uma multiplicidade criativa - e momentos fundamentais de recolhimento relativo e estratégico para re-existir (HAESBAERT, 2011). Essa autonomia relativa requer, necessariamente, uma base territorial, exclusiva ou não, onde cada cultura possa se reproduzir material e simbolicamente. Dessa forma, sustentamos que um Estado plurinacional é necessariamente um Estado pluriterritorial, no qual aos diferentes grupos culturais seja garantido o direito a decidir autonomamente sobre seus espaços de vida e (re)produção.

A insistência da Revolución Ciudadana em priorizar o sujeito abstrato liberal em detrimento da aposta na construção de um Estado plurinacional/pluriterritorial atualiza e reforça a colonialidade e a desigualdade estrutural da sociedade equatoriana, incrementando o racismo e a violação das territorialidades dos povos e comunidades. Numa sociedade "nacional" fundada sobre formas de trabalho compulsório, no racismo e em um ordenamento territorial arbitrário e excludente, justificar a exploração da naturezarecurso e o sacrifício dos territórios ancestrais em nome do "bem comum", do "interesse nacional" e/ou da "vontade geral da cidadania" significa aprofundar estratégias que historicamente significaram a assimilação e, inclusive, a extinção da diferença.

Frente a isso, reafirmamos a necessidade de construção de uma Geografia decolonial, desde abajo, que explicite e analise os conflitos e processos de (des)ordenamento territorial a partir de outras perspectivas, desde aqueles(as) que vivem e percebem cotidianamente a imposição e opressão do Estado nacional sobre suas formas próprias de organização da vida e do espaço. Acreditamos que só assim será possível ressignificar e transformar as formas de conhecimento e de política dominantes, deslocando a plurinacionalidade do âmbito de um Estado e de um direito coloniais e apostando na politização de espaços cotidianos, onde com muito esforço e luta compartilhada os povos e comunidades semeiam territórios de esperança. 


\section{Notas}

1- Uma versão deste artigo foi originalmente publicada em espanhol no livro "Geografía Crítica para detener el despojo de los territorios: teorías, experiencias y casos de trabajo en Ecuador" (BAYÓN; TORRES, 2019). O artigo sintetiza contribuições de minha dissertação de mestrado "Estado plurinacional: tensões de territorialidades no processo de refundação do Estado equatoriano" (SILVEIRA, 2011) e do artigo "Nudos territoriales críticos del Ecuador plurinacional" (BONILLA et al., 2016), produzido conjuntamente com outros(as) companheiros(as) do Coletivo.

2 - Utilizamos aqui o termo "povos tradicionais" segundo discussão proposta por Little em sua análise sobre territórios sociais e povos tradicionais no Brasil. Ver: LITTLE, P. Territórios sociais e povos tradicionais no Brasil: por uma Antropologia da territorialidade. In: Anuário Antropológico/2002-2003. Rio de Janeiro: Tempo Brasileiro, 2004. Pp. 251-290.

3 - Para uma análise mais detalhada sobre a Geografia equatoriana, consultar: COLECTIVO DE GEOGRAFÍA CRÍTICA DEL ECUADOR. Geografiando para la resistência. Journal of Latin American Geography, Austin, vol. 16, n ${ }^{\circ}$ 1, pp.172-177, 2017.

4 - O primeiro, do qual a França é protótipo e que serviu de base para a formação da maior parte dos países da Europa ocidental e da América Latina, fundava-se na ideia de nação "política" e "cívica", onde a unidade do Estado era dada não pela base cultural e étnica, mas pelo território, no qual se agrupavam diferentes etnias pela livre adesão e por meio de um contrato social (SCHNAPPER, 1994). O contrato, que dava legitimidade à conformação de uma única nação sob a mesma instituição político-administrativa estatal, no entanto, não era de fato acordado por todas as etnias que viriam a conformar esse Estado, mas sim criado através de um pacto de elites, o que dava a esse Estado um caráter inerentemente colonial. Oriundo do pensamento Iluminista e da experiência revolucionária do fim do século XVIII, esse modelo considera a nação como "o conjunto de indivíduos que, independentemente de suas características culturais, se reúnem (...) para fundar o Estado. Isto é, não se impõe a 'nação cultural', mas sim a 'nação política', cujos limites não respeitam quase nunca as fronteiras étnicas nem as identidades historicamente conformadas" (DÍAZ-POLANCO, 2004: 35; tradução própria). Sendo assim, esse modelo dá origem a uma centralização que sufoca todas as outras experiências internas, conforme nos mostra Lafont (1971) em sua análise sobre o que denomina colonialismo interior na França. Esse tipo específico de colonialismo, que não se limita ao país em questão, consiste na submissão principalmente econômica, mas também política, social e cultural de determinadas etnias (dominadas) por outras dominantes dentro de um mesmo Estado-nação, dando origem a regiões "subdesenvolvidas" no interior de Estados ditos "desenvolvidos". Esse processo "divide em colonizadores e colonizados uma massa humana que tem os mesmos direitos cívicos" (LAFONT, 1971: 120; tradução própria). Segundo o autor, o mito da "nação-contrato" acabou muitas vezes sendo absorvido e naturalizado inclusive pelas etnias que não se beneficiavam desse acordo. Ainda assim, esse processo é até hoje fonte de conflitos na França por parte de distintos movimentos autonomistas regionais (vide o caso do País Basco, da Bretanha e da Occitânia), assim como em outros países que seguiram o modelo universalista, como a Espanha e a Itália, onde a questão das autonomias ainda está pendente. A título de exemplo, na Espanha, onde a Constituição reconheceu em 1978 as autonomias regionais, os objetivos de pleno autogoverno para as pátrias étnicas do país ainda estão longe de se concretizarem. Aí "as contradições apareceram quando chegou o momento de converter as disposições constitucionais em realidades legislativas e políticas" (RUDOLPH \& 
THOMPSON, 1992: 26); dessa forma, os temas relativos à manutenção da ordem pública, à administração de justiça e ao financiamento dos governos autônomos e seu funcionamento ainda não encontraram solução satisfatória aos anseios dos movimentos autonomistas, em grande parte freados pelo argumento de que podem significar o desmembramento do país. Essa situação se repete também nos Estados-nações conformados a partir do modelo do direito sanguíneo, surgido na Alemanha e adotado predominantemente por países da Europa Oriental. Ainda que teoricamente tenham se fundado sobre uma concepção étnica de Estado, com base na crença em uma ascendência, uma cultura e uma língua comuns que formavam a comunidade nacional, os Estados organizados com base no modelo jus sanguinis também se ampararam no mito da nação (aqui étnica) difundido a partir de um pacto de elites; a etnia pretensamente compartilhada não correspondia de fato às diferentes formações culturais regionais, tratando-se também de uma comunidade imaginada.

5 - Anderson (2008) criou a expressão que talvez melhor defina esse processo: a nação como comunidade imaginada, inerentemente limitada e soberana: "é imaginada porque mesmo os membros das menores nações não conhecerão jamais à maioria de seus compatriotas, não os verão nem ouvirão sequer falar deles, mas na mente de cada um vive a imagem de sua comunhão. (...) A nação se imagina limitada porque inclusive a maior delas, que alberga talvez bilhões de seres humanos vivos, tem fronteiras finitas, ainda que elásticas, além das quais se encontram outras nações. (...) Imagina-se soberana porque o conceito nasceu em uma época em que a Ilustração e a Revolução estavam destruindo a legitimidade do reino dinástico hierárquico, divinamente ordenado. (...) as nações sonham, em ser livres (...) e a garantia e o emblema desta liberdade é o Estado soberano. Por último, se imagina como comunidade porque, independentemente da desigualdade e da exploração que de fato possam prevalecer em cada caso, a nação é concebida sempre como um companheirismo profundo, horizontal" (ANDERSON, 2008: 23-25; tradução própria).

6 - Segundo Souza (1998), a centralização do Estado-nação ultrapassa a da monarquia absoluta. No Estado Absolutista, "o poder era personalizado, identificava-se com a pessoa do soberano, e consequentemente podia ser controlado e responsabilizado o seu titular. (...) Esse controle e essa racionalização ficaram sendo muito mais difíceis nos regimes modernos de organização das sociedades políticas, tais como se constituíram a partir da Renascença. Viu-se, daí por diante, a força do poder político amparada pela "razão de Estado" segundo o pensamento de Maquiavel, com a soberania atribuída a todo o povo e, por isso mesmo, a autoridade diluída no anonimato. (...) A despersonalização do poder, longe de ter sido uma vitória sobre o absolutismo, veio acentuá-lo e fortalecê-lo ainda mais na forma de absolutismo estatal. À medida que o Estado vai crescendo em dimensões, mais difícil se torna a limitação do poder político e a realização do ideal de um Estado de direito. E, por isso, o "Estado constitucional" do século passado, e das primeiras décadas do atual, vai-se transformando no Estado administrativo e tecnocrático" (SOUZA, 1998:209; grifo nosso).

7 - É verdade que "onde a supremacia da nacionalidade estatal e da língua estatal não estava em questão", foi possível acolher as tradições das comunidades menores, transformando-as em folclore, "ao menos para provar o espectro de cores de sua palheta macro-nacional" (HOBSBAWM, 2002: 47). No entanto, em uma perspectiva macro, a maior parte das comunidades foi submetida à cultura hegemônica, processo que teve como base um pensamento eurocêntrico e universalista, como explicitado por Hobsbawm: “(...) ninguém chegou a negar, nunca, a real multinacionalidade ou multilingualidade ou multietnicidade dos mais antigos e inquestionáveis Estados-nações, ou seja, Grã-Bretanha, França ou Espanha. Que os "Estados-nações" seriam 
nacionalmente heterogêneos nessa forma foi algo prontamente aceito (...). Contudo, $a$ heterogeneidade nacional dos Estados-nações foi aceita sobretudo porque parecia claro que as nacionalidades pequenas, e especialmente as pequenas e atrasadas, só tinham a ganhar fundindo-se em nações maiores e fazendo, através destas, sua contribuição para a humanidade. (...) Uma vez aceito que uma nação independente ou "real" teria também que ser viável pelos critérios então definidos, seguia-se que algumas das menores nacionalidades e línguas estavam fadadas a desaparecer como tal" (2002: 45; grifo nosso).

8 - No caso dos nascentes Estados-nações da América Latina, formados com base no modelo universalista da "nação-contrato", esse processo significou uma reatualização do padrão de poder colonial, tendo por base as ideias de progresso e civilização impostos pela elite criolla sobre os grupos indígenas e negros, que não eram considerados cidadãos e ocupavam as classes mais exploradas do continente na condição de servos e escravos, respectivamente. A partir da releitura do trabalho de Lafont (1971) sobre a experiência francesa, González Casanova (2007) criou um conceito chave para entendermos a formação social, econômica e territorial latino-americana: colonialismo interno. Nas palavras do autor: "a definição do colonialismo interno está originalmente ligada a fenômenos de conquista, em que as populações de nativos não são exterminadas e formam parte, primeiro do Estado colonizador e depois do Estado que adquire uma independência formal, ou que inicia um processo de libertação, de transição para o socialismo, ou de recolonização e regresso ao capitalismo neoliberal. Os povos, minorias ou nações colonizadas pelo Estado-nação sofrem condições semelhantes às que os caracterizam no colonialismo e no neocolonialismo em nível internacional: 1) habitam em um território sem governo próprio; 2) encontram-se em situação de desigualdade frente às elites das etnias dominantes e das classes que as integram; 3) sua administração e responsabilidade jurídico-política concernem às etnias dominantes, às burguesias e oligarquias do governo central ou aos aliados e subordinados do mesmo; 4) seus habitantes não participam dos mais altos cargos políticos e militares do governo central, salvo em condição de 'assimilados'; 5) os direitos de seus habitantes, sua situação econômica, política, social e cultural são regulados e impostos pelo governo central; 6) em geral os colonizados no interior de um Estado-nação pertencem a uma 'raça' distinta da que domina o governo nacional e que é considerada 'inferior', ou ao cabo convertida em um símbolo 'libertador' que forma parte da demagogia estatal; 7) a maioria dos colonizados pertence a uma cultura distinta e não fala a língua "nacional"' (GONZALEZ CASANOVA, 2007). O colonialismo interno, além disso, tende a se conjugar com o colonialismo transnacional, ampliando assim a situação de submissão das classes inferiorizadas, na medida em que, articulados, "tendem a realizar expropriações e saques de territórios e propriedades agrárias existentes, e contribuem à proletarização ou empobrecimento por depredação, desemprego, baixos salários da população e dos trabalhadores das zonas subjugadas" (GONZÁLEZ CASANOVA, 2007). Mais do que "apenas" um problema de colonialismo interno, a questão da submissão racial e de classe dos indígenas e negros é ainda mais ampla, resultado da imbricação de diferentes estratégias hierarquizantes do padrão de poder moderno-colonial, dentre as quais figura, é claro, a hegemonia da forma Estado.

9 - A des-re-territorialização vem sendo utilizada como alternativa conceitual à desterritorialização, na medida em que esta é entendida como "um processo indissociavelmente ligado à sua contraface, os movimentos de (re)territorialização" (HAESBAERT, 2007b: 19).

10 - Uma análise mais completa e detalhada sobre o processo de formação territorial do Equador e dos conflitos territoriais mais recentes pode ser encontrada no artigo 
anteriormente citado "Nudos territoriales críticos en Ecuador: dinámicas, cambios y límites en la reconfiguración territorial del Estado" (BONILLA et al., 2016).

11 - Termo proposto por González Casanova (2007) para ressaltar a dimensão colonial e arbitrária dos processos de expropriação de terras e recursos através de distintas e renovadas frentes de expansão capitalista.

12 - Os chamados criollos eram os descendentes de espanhóis (brancos e mestiços) que, por seus privilégios raciais, haviam se consolidado como classe dominante na colônia.

13 - As chamadas haciendas eram grandes propriedades agrícolas fundadas no começo da colonização à custa da expropriação das terras indígenas na região Sierra (Cordilheira dos Andes). Com base na servidão indígena e concentrada em mãos de uma pequena elite de grandes proprietários rurais e da Igreja, a produção das haciendas era voltada para o consumo local e para a agro-exportação regional. O sistema de haciendas na serra andina equatoriana se estendeu até a década de 1960, quando foi realizada a primeira reforma agrária do país e a servidão foi abolida. Optamos por manter o termo no original, por se tratar de uma estrutura socioeconômica específica da realidade equatoriana, cujas especificidades não podem ser exatamente traduzidas por seu correlato em português. Para entender mais sobre a história e o funcionamento deste sistema, recomendo a leitura de: GUERRERO, Andrés. La semántica de la dominación: el concertaje de indios. Quito, Libri-Mundi, 1991.

14 - A importância estratégica que têm ganhado algumas áreas do planeta, ricas em recursos minerais, potencial energético e/ou biodiversidade e que, por processos histórico-espaciais, se encontram justamente em áreas que recentemente vêm sendo reivindicadas pelo movimento indígena, faz com que este tema ganhe especial relevância, mesmo em países em que a população indígena não é quantitativamente significativa (PORTO-GONÇALVES, 2001b). Para Little, a existência dessa biodiversidade "pode ter resultado das distintas formas de apropriação e proteção da natureza por parte de diferentes grupos sociais - isto é, a sociodiversidade - em processos de "coevolução"" (2004: 22).

\section{Referências bibliográficas}

ANDERSON, Benedict. Comunidades imaginadas. Reflexões sobre a origem e a difusão do nacionalismo. São Paulo: Companhia das Letras, 2008.

AYALA MORA, Enrique. Resumen de historia del Ecuador. Quito: Corporación Editora Nacional, 1999.

BAYÓN, Manuel; TORRES, Nataly (coord). Geografía Crítica para detener el despojo de los territorios: teorías, experiencias y casos de trabajo en Ecuador. Quito: Abya Yala, 2019.

BONILLA, Omar; MALDONADO, Paola; SILVEIRA, Manuela; BAYÓN, Manuel. Nudos territoriales críticos en Ecuador: dinámicas, cambios y límites en la reconfiguración territorial del Estado. GeoGraphos, Alicante, vol. 7, nº 84, pp.66-103, 2016.

DÍAZ-POLANCO, Hector. El canon Snorri. Diversidad cultural y tolerancia. México DF: Universidad de la Ciudad de México, 2004.

GELLNER, Ernest. Naciones y nacionalismo. Madrid: Alianza Editorial, 1988.

GONZÁLEZ, Jorge (ed.). Nación y Nacionalismo en América Latina. Bogotá/Buenos Aires: CES/CLACSO, 2007.

GONZÁLEZ CASANOVA, Pablo. Colonialismo interno (uma redefinição). In: BORON, Atilio; AMADEO, Javier; GONZALEZ, Sabrina (comp.). A teoria marxista hoje. Problemas e perspectivas. Buenos Aires: CLACSO, 2007. 
GUERRA, Emerson. Terras Indígenas e Desordenamento Territorial das Terras Timbira ao Xingu. Tese de doutorado - Programa de Pós-Graduação em Geografia da Universidade Federal Fluminense, Niterói, 2012.

HAESBAERT, Rogério. O mito da desterritorialização: do "fim dos territórios" à multiterritorialidade. Rio de Janeiro: Bertrand Brasil, 2007(a).

. Território e multiterritorialidade: um debate. GEOgraphia, Niterói, n ${ }^{\circ}$ 17, ano IX, pp. 19-45, 2007(b).

Dos múltiplos territórios à multiterritorialidade. In: HEIDRICH, Álvaro; COSTA, Benhur; PIRES, Cláudia; UEDA, Vanda (org). A emergência da multiterritorialidade: a ressignificação da relação do humano com o espaço. Canoas/Porto Alegre: Ed. ULBRA/EdUFGRS, 2008.

Viviendo en el límite: los dilemas del hibridismo y de la multi/transterritorialidad. In: ZUSMAN, Perla; HAESBAERT, Rogério; CASTRO, Hortensia; ADAMO, Susana (ed.). Geografías culturares: aproximaciones, intersecciones y desafios. Buenos Aires: Ed. Filo-UBA, 2011.

HOBSBAWM, Eric. Nações e nacionalismos desde 1780. Rio de Janeiro: Paz e Terra, 2002.

LACOSTE, Yves. La geografía: un arma para la guerra. Barcelona: Anagrama, 1990.

LAFONT, Robert. La revolución regionalista. Barcelona: Ediciones Ariel, 1971.

LANDER, Edgardo. Ciências sociais: saberes coloniais e eurocêntricos. In: LANDER, Edgardo (org.). A colonialidade do saber: eurocentrismo e ciências sociais. Buenos Aires: CLACSO, 2005.

LITTLE, Paul. Territórios sociais e povos tradicionais no Brasil: por uma Antropologia da territorialidade. In: Anuário Antropológico/2002-2003. Rio de Janeiro: Tempo Brasileiro, 2004.

MANN, Michael. O poder autônomo do Estado: suas origens, mecanismos e resultados. In: HALL, John (org.). Os Estados na História. Rio de Janeiro, Imago, 1992.

MORAES, Antônio Carlos. A dimensão territorial nas formações sociais latinoamericanas. Revista do Departamento de Geografia da USP, São Paulo, nº , pp. 81-86, 1994.

Território e História no Brasil. São Paulo: Anablume, 2005.

PORTO-GONÇALVES, Carlos Walter. Geo-grafías: movimientos sociales, nuevas territorialidades y sustentabilidad. México DF: Siglo XXI, 2001(a). Amazônia, Amazônias. São Paulo: Contexto, 2001(b). Geografando nos varadouros do mundo. Brasília: Ibama, 2003.

. A globalização da natureza e a natureza da globalização. Rio de Janeiro: Civilização Brasileira, 2006.

POULANTZAS, Nicos. O Estado, o poder, o socialismo. Rio de Janeiro: Paz e Terra, 1981.

RUDOLPH, Joseph; THOMPSON, Robert (ed). Ethnoterritorial Politics, Policy and the Western World. Boulder: Lynne Rienner, 1992.

SCHNAPPER, Dominique. La communauté des citoyens. Sur l'idée moderne de nation. Paris: Gallimard, 1994.

SOUSA, José; GARCIA, Clóvis; CARVALHO, José. Dicionário de Política. São Paulo: T.A Queiroz, 1998.

SVAMPA, Maristela. Consenso de los commodities, giro ecoterritorial y pensamiento crítico en América Latina. OSAL-Observatorio Social de América Latina, Buenos Aires, $\mathrm{n}^{\mathrm{o}}$ 32, pp.15-38, 2012. 